\title{
El sujeto popular y la renovación de las formas políticas. El caso argentino
}

\author{
Ignasi Brunet, Alejandro Pizzi \\ Universitat Rovira i Virgili \\ ignasi.brunet@urv.cat, alejandro.pizzi@urv.cat
}

Resumen: El artículo tiene por objetivo reflexionar sobre la vinculación entre la dinámica del capitalismo, la acción estatal y la constitución/movilización de sujetos colectivos. Analizamos esta vinculación con el caso particular de la movilización social en Argentina, destacando los procesos más salientes del vinculo entre transformaciones económicas, políticas y laborales, así como su impacto sobre las viejas/nuevas formas de movilización. En particular, se expone la problemática de la renovación de las formas políticas llevadas a cabo por el sujeto popular.

Palabras clave: movilización, clase social, ciclo de protestas, neoliberalismo.

Abstract: The aim of this article is to reflect on the link between the dynamics of capitalism, state action and the constitution/mobilization of collective subjects. We analyze this link in the particular case of social mobilization in Argentina and we highlight the salient processes of the link between economic, political and labour transformations as well as its impact on the old/new forms of mobilization. In particular, it discusses the problem of renewing political forms carried out by the popular subject.

Keywords: Mobilization, social class, cycle of protests, neoliberalism. 


\section{Introducción}

Las transformaciones sociales, económicas, políticas, culturales y tecnológicas que impulsa el actual mundo turbo-competitivo (Luttwak, 2003; Fernández Steinko, 2002; Keane, 2008), que extrae su fuerza social de la fuerza político-económica de aquellos cuyos intereses expresa (Bourdieu, 1999), con el derrumbe de la condición salarial y el debilitamiento que ello comporta para los trabajadores y los sectores populares (Castel, 1997), nos interroga sobre la forma en que las categorías heterogéneas de asalariados y el resto de sectores perjudicados por dichos cambios puedan forjar un actor colectivo. Este desafío, que remite a una nueva cuestión social (Rosanvallon, 1995) y a la misteriosa curva de la línea recta que va del análisis de la realidad de la clase obrera y popular a la necesidad de su organización política (Hardt y Negri, 2002), nos plantea una reflexión sobre el lugar que ocupa actualmente, en la teoría social, el sujeto popular, sus posibilidades de actuación colectiva, y las formas de analizarlas. Planteamiento que se apoya en el hecho de que si tomamos como referencia la fuerza de trabajo global veremos, como indica Munck (2002), que el número de sus miembros se duplicó entre 1965 y 1998, y es que la globalización en su forma moderna es un proceso cuya base no es tanto la proliferación de computadoras como la proliferación de proletarios (Coates, 2000). Esta proletarización masiva es, al menos, un rasgo tan característico de la globalización como el incremento de la movilidad del capital (Brunet y Pizzi, 2011).

El artículo constituye una reflexión sobre la vinculación inherente entre la dinámica del capitalismo, la acción estatal y la constitución/movilización de sujetos colectivos. Para ello presentamos, en primer lugar, una interpretación teórica sintética de la movilización social y la conformación de sujetos colectivos en las sociedades capitalistas actuales. En segundo lugar, ilustramos este proceso con el caso particular de la movilización social en Argentina en las últimas dos décadas debido a que, en cierta forma, desempeñó el papel de «laboratorio» de las políticas neoliberales. En el mismo destacamos los procesos más sobresalientes del vínculo entre transformaciones económicas, políticas y laborales, por un lado, y su impacto sobre las viejas/nuevas formas y lógicas de movilización, por otro. En particular, se remarca la crisis política desatada por la movilización generalizada y los intentos posteriores de reconstituir hegemónicamente la legitimidad estatal previamente cuestionada. Por último, desarrollamos unas conclusiones que, en función de los desarrollos teóricos y empíricos previos, reflexionan sobre la dialéctica entre movilizaciones y acción estatal. 


\section{Conflicto y acción colectiva}

\subsection{Espacio de los movimientos sociales y nuevas lógicas de acción colectiva}

Rancière (2005) plantea que tras la aparición de la política, la sociedad existe de un modo particular: como sociedad del conflicto, y los sujetos existen en el proceso de anunciarse en ese conflicto. De aquí que los movimientos sociales no preexisten al momento del conflicto, sino que se constituyen en él. Específicamente, para Negri (2006a) los movimientos sociales operan sobre dos planos: sobre el plano impuesto por las instituciones establecidas, en el que las cosas se suceden como si no hubiera más que un solo mundo posible, y sobre el plano elegido por los propios movimientos sociales, que es el de la lógica de lo instituyente, de la invención, de la creación y la efectuación de una multiplicidad de mundos posibles. Como indica Lazzarato (2006: 180), el poder establecido «no puede reconocer esta nueva dimensión so pena de implosión, de desmoronamiento de sus instituciones; y los movimientos sociales no pueden retirarse a la creación de sus mundos e ignorar el mundo de la política institucional, so pena de impotencia». Por ello, en vez de pensar la realidad como la articulación de dos niveles jerarquizados (la infraestructura como fundamento de la superestructura), se ha de pensar lo real en un solo nivel: el de la institución (Castoriadis, 1993; Lourau, 2001) o también bajo una representación pluridimensional (Bourdieu, 2000), en el sentido de que el mundo social está constituido por una pluralidad de campos relativamente autónomos y cada campo está estructurado por relaciones de dominación. Esta pluralidad de formas de dominación lleva a mecanismos específcos de capitalización de los recursos o capitales que son propios de los diferentes campos: no sólo el capital económico, sino también el cultural, político, etc.

Bajo esta representación pluridimensional, Bourdieu (2002) plantea una teoría de los capitalismos asociados en el seno de una misma sociedad (como la sociedad española o las latinoamericanas), y no la de un capitalismo único y unificado con un significado principalmente económico. Sin embargo, las capitalizaciones se articulan de manera compleja en el seno de las sociedades actuales, con el peso particular de la dinámica de acumulación del capital económico (Corcuff, 2009), aunque la noción de «autonomía relativa» de los campos indica que lo que sucede en el campo político no es necesariamente dirigido, aun «en última instancia», por lo que sucede en el campo económico. El hecho de que el mundo está dividido en una multiplicidad de ámbitos de actividad distintos — se llamen «campos», «espacios», «sectores» o «mundos»- explica la propuesta de Mathieu (2004) del concepto de espacio de los movimientos sociales para señalar las especificidades 
del universo que constituyen las movilizaciones de protesta, así como también el tipo de vínculos, complejos y fluctuantes, que lo unen al campo político, es decir, al de la política institucional y partidista (Corcuff y Mathieu, 2011).

Tarrow (1997) argumenta que la acción colectiva en los movimientos sociales no responde a un modelo de universalidad, sino que se presenta como un conjunto de prácticas de intervención que, en determinadas situaciones, intenta $-y$ en ocasiones lo logra- obtener mayores oportunidades o mejorar las condiciones de los agentes. En este sentido, en el capitalismo los trabajadores urbanos racionalizaron el repertorio tradicional de protesta popular e inventaron un método sistemático de organizar las reivindicaciones colectivas cuyo sello distintivo, para Tilly y Wood (2009), son las demostraciones públicas que implican exhibiciones de valor u orgullo, afirmación de la identidad y la unidad, expresada en una simbología uniforme, la importancia del número de manifestantes y el compromiso con la causa que se defiende. A lo largo de los siglos xIx y xx, esta nueva metodología reivindicativa se institucionalizó con las movilizaciones de los movimientos sociales. Pero a pesar de que éstos sean presentados a menudo como una disrupción de la norma que introduce caos y desorden, en sí mismo no son en absoluto caóticos o desordenados. Como indica Tilly $(1986,2004)$, las autoridades y ciertos historiadores imprudentes describen a menudo la agitación popular como desorden, pero cuanto más de cerca examinamos la confrontación, más orden descubrimos. Descubrimos un orden creado por el arraigo de la acción colectiva en las rutinas y en la organización de la vida social cotidiana, y por su implicación en un proceso continuo de señalización, negociación y lucha con otras partes cuyos intereses se ven afectados por la acción colectiva. Su acción y su eficacia explican que los movimientos sociales incidan en la gestión de un conflicto social que actúa, a su vez, como desencadenante del movimiento del actor colectivo.

Ante el agotamiento de la forma representativa de los poderes formalmente democráticos en los estados capitalistas, donde «una representación permanente equivale a una hegemonía de los representantes sobre los representados» (Michels, 1971: 38), tanto los teóricos de la teoría postobrerista italiana (Virno, Negri, Marazzi, Lazzarato, etc.) como los referentes de la teoría de los nuevos movimientos sociales (Touraine, Habermas, Offe, Melucci, etc.), plantean que las nuevas lógicas de acción colectiva, es decir, las que nacieron a partir de la década de 1970, especialmente en Europa y en EE.UU., no serían sino una forma de protesta social específica de las sociedades posindustriales, igual que el movimiento emancipatorio burgués lo fue de los siglos XVIII y XIX, y el movimiento obrero lo fue de los siglos XIX y xx. Con esto se quiere decir, desde la perspectiva de los posobreristas, que los nuevos movimientos sociales son el resultado del rechazo al 
trabajo fordista; rechazo fundamental en los movimientos italianos de las décadas de 1960 y 1970 . En estos movimientos, el rechazo de la sociedad salarial fordista, cuya riqueza, incluso en el mejor de los casos, supone una esclavitud de por vida para los trabajadores, implica plantearse cuáles son las exigencias tecnológicas de los procesos productivos en vez de mitificar acríticamente la figura del trabajador (Balestrini y Moroni, 2007). Desde la perspectiva de la teoría de los nuevos movimientos, éstos son el resultado de conflictos específicos de las sociedades del capitalismo tardío. En estas sociedades, los Nuevos Movimientos Sociales se constituyen, para Touraine $(1985,1991)$, en el plano de poder decidir el sentido de la propia historicidad, al constituir este plano el síntoma del conflicto central en la sociedad del capitalismo tardío o posindustrial. Conflicto en el que la figura del Sujeto se opone a la potencia de un sistema global e impersonal de dominación; sistema que ha producido una crisis del Estado social que se ha saldado con la victoria de posiciones privatizadoras neoliberales y el continuo proceso de precarización y de deterioro de las condiciones de vida.

Por su parte, desde la sociología de los campos políticos contemporáneos de Bourdieu $(1997,2008)$, se observa en los movimientos sociales actuales una activación de un espíritu crítico con respecto a la «delegación», lo que ha alimentado un rechazo de la dominación política, basada en los mecanismos de capitalización política (de apropiación y monopolización de un capital político). Es así como Bourdieu analiza la dominación política como uno de los modos de dominación propios de las sociedades post-68, en el sentido de que la representación política constituye una desposesión de los profanos en beneficio de los profesionales, de los representados en beneficio de los representantes. De aquí la ambigüedad inherente a la misma lucha política, ya que este combate por las «ideas» y los «ideales» es también inseparablemente un combate por los poderes y, se quiera o no, por privilegios.

\subsection{Movilización de recursos y clases sociales}

La teoría de la movilización de recursos centra su interés en el análisis comparado de las infraestructuras organizativas de los actores «con el objetivo de comprender mejor los patrones históricos de movilización y predecir cuáles facilitan la emergencia, eficacia y consolidación de los movimientos» (Ibarra et alii, 2002: 40). Por tanto, su principal preocupación es estudiar la eficacia con que las distintas organizaciones (que juntas conforman un movimiento social) hacen uso de los recursos disponibles para la consecución de objetivos (Snow et alii, 1980; McCarthy, 1996; Kriesi, 1996). 
Dentro de este enfoque, la Escuela de las Oportunidades Políticas plantea que los individuos se suman a los movimientos sociales como respuesta a las oportunidades políticas, y en su dinámica posterior crean nuevas oportunidades a través de la acción colectiva: «Los movimientos surgen cuando se amplían las oportunidades políticas, cuando se demuestra la existencia de aliados y cuando se pone de relieve la vulnerabilidad de los oponentes» (Tarrow 1997: 58). Estas oportunidades, que son evaluadas por los protagonistas y constituyen los incentivos (sociales) para actuar colectivamente, implican coyunturas que reducen los costos de la movilización, en la medida en que los actores descubren aperturas institucionales, élites vulnerables o sinergias con otros procesos sociales (McAdam, 1988).

Un factor vinculado a las oportunidades políticas, y que constituye un recurso que facilita la movilización, son los repertorios de la acción colectiva (Tilly, 1978, 2002), referidos a los modos recurrentes de acción que llevan a cabo los movimientos sociales. Formas de movilización reconocidas a través del tiempo y del espacio, y que son productos culturales aprendidos que surgen y cobran forma a partir de confrontaciones anteriores, y se van transformando en función de las fluctuaciones en los intereses, las oportunidades y la organización de los movimientos sociales. Otro concepto que vincula las oportunidades políticas con la movilización es el «ciclo de protestas», observable cuando, bajo una determinada constelación de circunstancias, el conflicto protagonizado por uno o varios movimientos sociales se generaliza en el sistema social hasta constituir un ciclo de protesta, que configura una fase de intensificación del conflicto y del enfrentamiento a lo largo del sistema social (Tarrow, 1997, 2002).

Desde esta Escuela, la movilización posee una dimensión cultural insoslayable, porque los individuos no pueden emplear rutinas de acción colectiva que desconocen. Cada sociedad tiene una reserva de formas familiares de acción, conocidas tanto para los activistas y promotores como por sus oponentes, que son productos/convenciones culturales. De aquí que para la Escuela del Proceso Colectivo de Interpretación las oportunidades políticas y la movilización social son el resultado de un proceso de rupturas culturales que hacen aflorar a la superficie contradicciones latentes (Zald, 1999), y que reformulan o cuestionan las definiciones estándar de la situación social que es objeto de críticas por parte de los movimientos. Desde esta última Escuela, una tarea fundamental de los movimientos consiste en: 1) señalar agravios e injusticias; 2) vincularlos a otros agravios para visualizar una trama política más compleja de injusticias; 3 ) argumentar posibles soluciones a los problemas planteados, y 4) construir marcos de significados más amplios que puedan encontrar eco en la predisposición cultural de una población 
(Ibarra et alii, 2002). No obstante, la creación de marcos de significado constituye un proceso de lucha y negociación interna entre distintos agentes que defienden puntos de vista divergentes dentro de un movimiento social. Estos marcos en disputa dentro del movimiento se fundamentan en las luchas por imponer un sentido sobre las oportunidades políticas, las organizaciones y las estrategias a seguir.

La teoría de la movilización de recursos, con sus diferentes subescuelas, proporciona categorías útiles para el análisis de la acción colectiva, pero no tiene un desarrollo sistemático sobre la disponibilidad estructuralmente diferenciada de los recursos entre distintos sectores de la población que corresponden a diferentes clases sociales. Pero consideramos que, especialmente en su versión de las oportunidades políticas, puede integrarse en una visión dinámica de relaciones entre clases sociales, de los mecanismos de explotación y dominación (Mouriaux y Beroud, 2000), al incorporar la dimensión clasista del conflicto como variable estructural. La misma determinaría que las distintas clases sociales tienen a su disposición diferentes medios y recursos de acción (Wright, 1994), dada la estructura de desigualdad material de la sociedad, para obtener mejoras en su bienestar social y económico. En consecuencia, la teoría de la movilización de recursos se puede articular con la estructuralmente diferente distribución de recursos (económicos, sociales, políticos y culturales; materiales e inmateriales) y oportunidades de los que disponen las clases sociales en las sociedades capitalistas. En este sentido, la posición estructural en la sociedad restringe los medios a disposición de la clase obrera para luchar por mejoras en su bienestar material, a la vez que también las oportunidades políticas que se les presentan a diferentes grupos sociales están vinculadas a su posición en la estructura de desigualdad material y al poder subyacente de los mismos (Poole, 1995).

El concepto de oportunidades políticas resalta, además, la centralidad de los ordenamientos institucionales, los cambios de gobiernos y/o divisiones entre las élites dirigentes, y la capacidad estatal de represión, como variables fundamentales para la caracterización de tales oportunidades. Sin embargo, esta dimensión puede incorporar la consideración de las relaciones de poder estructurales entre las clases sociales que, en cada período histórico, configuran una formación social determinada. Tal consideración estructural permitiría comprender el surgimiento de oportunidades con mayor robustez y sistematicidad, y articularlas en una dinámica social estructural, de medio o largo plazo. Además, existe, tal y como hemos expuesto, un concepto relevante en este marco teórico de la movilización de recursos, los «repertorios de acción colectiva», que vincula las transformaciones estructurales que experimenta una sociedad con sus formas de movilización. 
Para este enfoque, en tanto conjunto de medios de los que dispone un grupo particular para realizar reclamos, los repertorios no se pueden comprender sólo como los medios más adecuados para alcanzar el fin deseado por un grupo en determinadas circunstancias, sino que también deben pensarse en términos de aprendizaje. Por ejemplo, la huelga es un medio típico de protesta empleado por los trabajadores en las sociedades industriales. Sin embargo, esto no implica que sea siempre el medio más eficaz, sino que es utilizado con frecuencia en los conflictos laborales porque constituye una herramienta incorporada, en un contexto de aprendizaje, en el mundo obrero. En este sentido, las oportunidades no son independientes de las relaciones de poder/saber de los sujetos involucrados. Y a escala estructural, la dimensión de clase tiene relevancia teórica en la medida en que la pertenencia a una determinada clase social priva sistemáticamente de ciertos repertorios de acción y favorece otros para que el grupo pueda impulsar sus demandas de bienestar.

Por tanto, desde nuestra perspectiva, hay que aunar los repertorios de acción colectiva con las determinaciones de clase del grupo social movilizado. Esto es coherente con la perspectiva de Wright (1994) de centrarse en los intereses instrumentales (materiales) de las clases, porque éstas cuentan con medios distintos, impuestos por la estructura de desigualdad material, para luchar por sus objetivos de bienestar. Dicho de otra manera, las condiciones de posibilidad del uso de determinados repertorios de acción están dadas por las posiciones de clase de los actores movilizados, porque en el contexto de estas restricciones estructurales es donde se desenvuelven determinadas prácticas de lucha y movilización, y que constituyen herramientas de acción incorporadas por medio de un proceso de aprendizaje colectivo. En su modelo de estructuración de las clases sociales, Wright incorpora la dimensión de la dominación, y por tanto la política y la ideología juegan un papel determinante sobre las pautas de acción colectiva. Debido a que muchas posiciones de clase son duales o contradictorias, su traducción a formaciones de clase dependerá de los procesos sociales que movilizan la acción colectiva, confiriendo un papel teórico a los determinantes políticos e ideológicos; de ahí la importancia, para Bourdieu (2000), de las luchas de clasificación social en torno a lo que son efectivamente las diferencias de clases en una sociedad dada: es decir, las luchas simbólicas alrededor de la definición y de sus fronteras, que constituyen una de las modalidades de la lucha de clases. De esta forma, la relación entre la posición de clase (la clase en sí) y la acción colectiva (la clase para sí) está mediada por la curvatura de la política. La manifestación política y organizativa de las clases, y por tanto la acción colectiva, no presenta un vínculo directo y rígido con la dimensión ocupacional de la estructura de cla- 
ses. Sin embargo, sin por ello defender explicaciones mecanicistas o economicistas, no se puede considerar la dimensión política de las prácticas humanas sin tener en cuenta la clase probable, esto es, lo que existe potencialmente en virtud de las condiciones de existencia reflejadas en una serie de indicadores empíricos. Y es que los individuos que participan en prácticas políticas (la clase movilizada) se desenvuelven dentro de determinadas limitaciones y posibilidades que están dadas por su inserción en la estructura de desigualdad material (económica y política) de una sociedad.

\section{El caso argentino}

En términos de dominación política, el neoliberalismo en Argentina se apoyó sobre un proceso de disciplinamiento social, implementado mediante el terrorismo de Estado, llevado a cabo por la dictadura militar (1976-1983), que se profundizó posteriormente por otro proceso de disciplinamiento constituido por una dinámica hiperinflacionaria entre los años 1989 y 1990 (Villarreal, 1985; Lobato y Suriano, 2003; Basualdo, 2006). Bajo el gobierno peronista de Carlos Saúl Menem (1989-1999), el neoliberalismo se institucionalizó mediante un pacto de gobernabilidad entre el Partido Justicialista, el establishment empresario y las organizaciones sindicales dominantes, con acompañamiento de un sector importante de la sociedad civil. De esta manera, se avanzó en una profunda reforma del sistema económico a partir de una fuerte orientación pro-mercado (Basualdo, 2000; Acuña, 1995, Palermo y Novaro, 1996). Las características de la movilización social que provocaron dichas reformas sobre los sectores urbanos, especialmente vinculados al mundo del trabajo, constituyen un ejemplo del concepto de espacio de los movimientos sociales, pero también de cómo las formas de manifestación, organización y acción de los sujetos populares están condicionadas por su vinculación estructural con la dinámica del capital y del Estado, es decir, de la política institucional y partidista, y que se explica por las determinaciones de clase del propio grupo social movilizado. Es decir, la relación entre la posición de clase y la acción colectiva está mediatizada por la dinámica de la política.

\subsection{Las movilizaciones de los 90}

La incorporación de Argentina al proceso de globalización neoliberal en los años 90 se tradujo en tres grandes transformaciones económicas y políticas, que impactaron fuertemente sobre el movimiento obrero organizado (Godio, 2006) y 
en sus repertorios de movilización y acción colectiva: 1) la consolidación de una democracia pluralista estable, con lo cual el sindicalismo hegemónico perdió la posibilidad de jugar el rol de representante del peronismo en épocas de proscripción política (su papel como «columna vertebral»); 2) la reforma económica con apertura y economía de libre mercado, lo cual debilitó la base industrial sobre la que se asentó tradicionalmente el movimiento obrero. Con este proceso, quedaron de manifiesto las dificultades objetivas para adecuar las estrategias sindicales frente a las reformas neoliberales, que generaron una estructura económica de grandes disparidades de productividad y competitividad, a la vez que el desempleo y el subempleo socavaron sus bases de sustentación históricas; 3) la mutación ideológica de los partidos tradicionales, a favor de las políticas pro-mercado y abandono de los proyectos nacional-populares, de base industrial y mercadointernistas. Constituyeron grandes procesos que limitaron las oportunidades políticas de actuación del movimiento obrero hegemónico y, a su vez, favorecieron las oportunidades para nuevas formas de expresión, y nuevas organizaciones, de los sectores populares.

Tras la consolidación del régimen neoliberal se destacan una serie de movilizaciones de la fragmentada clase trabajadora en Argentina (Cifarelli et alii, 2006; Cifarelli y Martínez, 2009) y algunos sectores medios empobrecidos, ocurrida a partir de los primeros años de la década de 1990, ya que la ofensiva capitalista iniciada globalmente con las políticas neoliberales comienza a encontrar ciertos límites sociales (Almeyra, 2005). Además, el movimiento de derechos humanos, que nació de la represión dictatorial y se expandió en la década de 1980 (Jelin, 1989), en los noventa asume un renovado protagonismo contra las políticas neoliberales (Randle, 1998; Dussell et alii, 1997). Por tanto, desde los primeros años de esta década se inició un ciclo de luchas de resistencia (Klachko, 2007; Iñigo Carreras y Cotarelo, 2003; Schuster et alii, 2005) que incluyeron a sectores de la clase obrera sindicalizada, pero también desde mediados de los 90 un creciente número de trabajadores desocupados comenzó a organizarse en torno a nuevas agrupaciones sociales, inaugurando nuevas formas de lucha. Los piquetes constituían, hasta ese momento, un repertorio consistente en clausurar el acceso a las empresas durante las grandes huelgas fabriles o generales. Pero sin empleo el único piquete posible consistía en bloquear el espacio de la circulación, cortando caminos y carreteras. En dichos piquetes se mantenían formas horizontales de organización: reuniones, asambleas, ollas populares, turnos de vigilancia (Svampa y Pereyra, 2003). De esta forma, repertorios y recursos de acción como el piquete, típicos de la clase trabajadora debido a las desiguales oportunidades de acción estructuralmente disponibles en una sociedad capitalista, en tanto pro- 
ductos culturales aprendidos de las generaciones anteriores, cobran vida y se actualizan en las nuevas confrontaciones.

Por otra parte, en esta década el movimiento sindical dominante, la Confederación General del Trabajo (CGT), cuyos dirigentes se concebían como parte del sistema de poder, se asoció subordinadamente con la coalición de empresarios impulsada por el menemismo (Palermo y Novaro, 1996). La ideología que los legitimaba, sus marcos de interpretación de la realidad elaborados en cursos de formación sindical, sostenía que la transnacionalización económica y la globalización financiera socavaban estructuralmente los medios de presión convencionales del sindicalismo (Godio, 2000). En su perspectiva, el nuevo escenario determinaba que la prioridad estratégica consistía en mantener relaciones verticales con los empresarios y con el Estado, mientras que el sindicato debía constituirse en un proveedor de servicios para sus afiliados (Rapoport, 2005). Sin embargo, durante la primera etapa del gobierno de Menem, previa a la aplicación del Plan de Convertibilidad, se incrementaron las manifestaciones de protesta motivadas sus políticas de ajuste económico (Auyero, 2002; Schuster y Nardacchione, 2005). Pero tras la implementación del plan económico, éstas se redujeron notablemente (Senén Gonzáles y Bosoer, 1999), debido a un proceso de cooptación mediante el otorgamiento, por parte del gobierno, de incentivos selectivos a los dirigentes gremiales, fundamentalmente vinculados a su participación en el proceso de privatizaciones de empresas públicas (Fair, 2008; Murillo, 1997).

Sin embargo, frente a las primeras medidas privatizadoras y de ajuste económico que lanzó el gobierno, se desataron una serie de huelgas, movilizadas por sectores opositores al oficialismo dentro de los sindicatos, en los sectores público, telefónico, ferroviario, así como en algunas automotrices. Pero la agitación social y sindical era «defensiva» porque carecían de una estrategia alternativa al proceso de reformas económicas en curso (Piva, 2001). En ese contexto, los trabajadores que se opusieron al avance neoliberal no pudieron evitar la derrota porque las reformas pro-mercado no encontraron una oposición consistente y unificada en el campo político, popular y/o sindical (Gómez, 1996). Así, el impacto del menemismo generó cuatro líneas políticas dentro del movimiento obrero: 1) el sindicalismo alineado con el menemismo; 2) cercanos a este sector se ubicaban sectores con una postura de pragmatismo negociador; 3) el Movimiento de Trabajadores Argentinos, más afines al peronismo histórico, liderado por los camioneros; 4) la Central de Trabajadores Argentinos (CTA), que expresaba posiciones socialcristianas peronistas aliadas con la izquierda marxista, y asumía formas de sindicalismo de movimiento social (Godio, 2000; Murillo, 1997). 
Se puede sostener que la consolidación del neoliberalismo provocó, en los años 90, dos etapas de resistencia y movilizaciones, esto es, dos ciclos de protesta. En la primera, los sectores sociales y sindicales movilizados (bancarios, docentes, transportistas, trabajadores públicos, jubilados) desplegaron estrategias de resistencias a la implementación de reformas. En la segunda, las resistencias se organizaron para enfrentar las consecuencia de la implementación de las reformas: achicamiento industrial, crisis de las economías regionales, alto desempleo (Gómez, 2006). En este sentido, los procesos de ajuste estructural, con la precarización y desempleo masivos consecuentes (Beccaria, 2001), generaron las condiciones para el surgimiento de nuevas modalidades de protesta colectiva de los sectores ligados al mundo del trabajo. A fines de 1993 comenzaron, y en los años siguientes se extendieron, las protestas en el interior del país vinculadas al ajuste de las administraciones públicas y a las crisis de las economías regionales. Los «estallidos sociales» en las provincias de Santiago del Estero, Jujuy, Salta y Tucumán darán inicio a una nueva forma de protesta social. Estallidos sociales protagonizados por trabajadores del sector público (provincial y municipal), que demandaban la defensa del empleo y de los salarios, recortados por una serie de fuertes ajustes fiscales. La forma de expresión dominante de esta modalidad fue la movilización y concentración callejera, mientras que el alcance de este tipo de protesta se circunscribía a las capitales y ciudades importantes de la provincia donde ocurría, a la vez que los destinatarios de la ira popular se focalizaban en el gobierno provincial y en la clase política local (Farinetti, 1999).

El crecimiento del desempleo dio origen a la aparición del movimiento de trabajadores desocupados, que demandaban organizadamente ayudas sociales y puestos de trabajo. Las primeras organizaciones surgieron en la provincia de Neuquén. También en Salta se formaron organizaciones de desocupados integradas por trabajadores despedidos de la empresa YPF (Svampa y Pereyra, 2003). A fines de 1994 se produjo el primer corte de ruta de los desocupados, que constituirá su principal herramienta de manifestación, y que luego será una modalidad de lucha habitual. De estas luchas sociales surgió la Comisión de la Asamblea de Desocupados, que fue el origen de los «piqueteros». Constituye un ejemplo de un nuevo sujeto novedoso, aunque proveniente de la clase obrera formal, que cobra existencia a partir de tomar la palabra y anunciarse activamente en el conflicto social. De esta manera, debido a las presiones que la Comisión ejerció sobre el gobierno se obtuvo la sanción de una ley que establecía un subsidio para los cabezas de familia desocupados (Quirós, 2008). Los piqueteros lograron organizarse sobre la base del quiebre de las tradiciones culturales y laborales de la sociedad salarial. No son movimientos propios de la pobreza clásica de los países subde- 
sarrollados, sino movimientos referenciados culturalmente en las tradiciones $y$ en la memoria de un pasado de pleno empleo y prácticas sindicales, promovidos por individuos que aspiran a reingresar en el mundo del trabajo asalariado. Sus miembros «no pertenecen al mundo de la marginalidad estructural, sino al mundo de una sociedad salarial desarticulada. Por eso son persistentes y organizados: tienen vínculos históricos con los sindicatos y con las organizaciones sociales barriales» (Godio, 2006: 120).

La última etapa del régimen de convertibilidad (1998-2001) profundizó el debilitamiento del modelo económico y una creciente movilización social de descontento aceleró el cuestionamiento a los canales de mediación entre Estado y sociedad (Auyero, 2002). La crisis fiscal y externa del Estado, bajo el gobierno de la Alianza (1999-2001), indujo a profundizar la flexibilización mediante la disminución de sueldos a empleados públicos y la reducción de los presupuestos para los planes sociales para desocupados (Damill et alii, 2007; Rapoport, 2005). De esta manera, el gobierno se enfrentaba con actores con alta capacidad de movilización y acción colectiva. Posteriormente, la confiscación de los depósitos bancarios de los ahorristas (Brunet y Schilman, 2004) incentivó la protesta callejera de las clases medias urbanas, mediante un novedoso instrumento de movilización: el cacerolazo (Schuster y Nardacchione, 2005). Su combinación con una ola de saqueos a comercios, por parte de sectores de la población más empobrecida, desató una escala masiva de protestas, incluyendo comerciantes, profesionales, cámaras empresariales, etc. La represión generalizada en las jornadas del 19 y 20 de diciembre de 2001 como única respuesta del gobierno, incluyendo el Estado de Sitio, dejó sin sustento político a aquél y, tras su caída, se profundizó la crisis social. En este sentido, no fue hasta 2001 cuando la explosión de demandas desbordó al sistema político.

\subsection{Crisis 2001-2002}

Las movilizaciones masivas de diciembre de 2001 se convirtieron en la metáfora de la descomposición del orden político. El conflicto se presentaba como insuperable a través de mecanismos normales como la negociación en el Congreso. La distancia entre las demandas y los canales institucionales favorecía la visualización de un espacio específico de la movilización social (Mathieu, 2007). Movilizaciones pluriclasistas que sostenían la consigna «que se vayan todos», y que estaban conformadas por las asambleas barriales (Muñoz, 2009), las organizaciones piqueteras, los movimientos de ahorristas y una masa numerosa de ciudadanos no organizados. Las asambleas barriales (Schuster y Nardacchione, 
2005), expresaban una crítica explícita al sistema político, pero no lograron tener un caracter organizado a escala nacional (Bloj, 2004). Las diferentes movilizaciones, unificadas en torno a esa consigna colectiva («que se vayan todos»), no avanzaron en la construcción política de un sujeto que permitiera consolidar una posición compartida más allá del rechazo.

Por su parte, la crisis de 2001-2002 abrió oportunidades políticas para un mayor crecimiento y fortaleza política del movimiento piquetero (Mazzeo, 2004). Su expansión estuvo conducida mayoritariamente por organizaciones como la Federación de Tierra y Vivienda (FTV) y la Corriente Clasista y Combativa (CCC). Lo que disputaban estas organizaciones era que la distribución de los planes sociales y subsidios a los desempleados quedara bajo su control, cuestionando que esa prerrogativa fuera manejada por los intendentes $y / o$ punteros políticos del justicialismo. A lo largo de 2001 se realizaron asambleas piqueteras que levantaron un programa de reivindicaciones sociales, pero fracasaron en el propósito de conformar un movimiento piquetero unificado. Hubo estrategias excluyentes por parte de distintas organizaciones y una clara asimetría en la capacidad de movilización de las corrientes más masivas, la FTV y CCC, con relación al resto de las agrupaciones, por lo cual para estos grupos más pequeños la asamblea conjunta no constituía un ámbito adecuado para la negociación. Tras el fin del gobierno de la Alianza, el movimiento piquetero se constituyó casi en la única oposición al gobierno peronista de Duhalde, y se erigieron en los portavoces de las demandas sociales en lugar de los sindicatos. De los 106.000 beneficiarios de planes de este tipo en 1999, se pasó a 1.200.000 en 2002, y a 2.200.000 en 2003. Sin embargo, los movimientos piqueteros no llegaron a manejar más del 10\% de estos recursos (Svampa y Pereyra, 2003).

Del mismo modo que el movimiento piquetero, el fenómeno de recuperación de empresas comenzó a expandirse debido a la vinculación entre la crisis socioeconómica objetiva, por un lado, y la capacidad de transmisión de esta experiencia entre trabajadores, gracias a la coordinación de la acción colectiva por medio de movimientos sociales, por otro. Entre los años 2001 y 2003 ya existían más de cien empresas recuperadas (Rebón, 2005). Hacia 2010, se calculaba que existían cerca de 200 empresas recuperadas en todo el país, con alrededor de 10.000 trabajadores vinculados a las mismas (Ruggeri, 2010). Si bien los trabajadores de estas empresas, como la mayoría de la sociedad en ese momento, estaban inmersos en el clima de impugnación general de la representación política, el movimiento como tal no sostuvo explícitamente un cuestionamiento directo al orden político entre sus consignas, sino la búsqueda alternativa de fuentes de trabajo, aunque su propia organización asamblearia y horizontal conllevara la posibilidad latente de un cuestionamiento radical del orden social. 
Lo que alentó este tipo de acción colectiva de los trabajadores fue la ausencia de respuesta al conflicto laboral por parte de los empresarios, las instituciones de intermediación laboral y (en muchos casos) las organizaciones sindicales. Por tanto, el contexto social y político ofrecía incentivos para aferrarse a esta alternativa de mantenimiento de la fuente laboral como último recurso visualizado por los trabajadores para no caer bajo la amenaza de la desafiliación social. En el momento en que comienzan a extenderse y hacerse visibles las recuperaciones de empresas (2002-2003), y a constituirse en un movimiento social nutrido de organizaciones formales, el contexto político general estuvo marcado por el hecho de que se había reducido el margen político para continuar con una salida represiva de la crisis social, tal como fue característico de los años inmediatos. Por el contrario, el Estado encauzó estos procesos favoreciendo la formación de cooperativas de trabajo, a la vez que rechazaba otras opciones, como la estatización de las empresas bajo el control obrero de la producción. De esta manera, se institucionalizaba el movimiento al conjugarse el plano instituyente del movimiento social con el plano de las instituciones establecidas.

Otro tipo de incentivos a su desarrollo estuvo impulsado por la dinámica del propio movimiento social, como la construcción de redes de asociaciones que facilitan la acción colectiva: la existencia de un know-how consolidado, promovido y difundido por organizaciones del movimiento de empresas recuperadas. Además, las conducciones de las empresas recuperadas han recibido incentivos para la constitución de organizaciones que articulen a las empresas recuperadas entre sí, junto con otros actores sociales con los que perciban ciertas afinidades sociopolíticas. Desde el propio inicio de este movimiento existieron diferentes criterios organizativos y alternativas políticas en juego, que estuvieron condicionadas, a su vez, por las propias propuestas estatales de encauzamiento del conflicto. Así, en primer lugar se ubica la opción de conformar una federación de cooperativas -Federación de Cooperativas de Trabajo de Empresas Recuperadas (FENCOOTER) - , vinculada orgánicamente al Estado mediante el Instituto Nacional de Economía Social (INAES). En segundo lugar, existió la alternativa de la estatización de las empresas junto con el control obrero de la producción, que implicaba rechazar la figura cooperativa, alternativa que estuvo conducida por fuerzas políticas y sindicales de izquierda. La ausencia de condiciones políticas determinó que esta variante no prosperara y, al cabo de pocos años, el espacio político que articulaba esta solución terminó agotándose. En tercer lugar, se halla la conformación de movimientos sociales autónomos de los partidos políticos, que apoyan pragmáticamente la adopción de la figura legal de cooperativa de trabajo, aunque originalmente no se identifican como federación de cooperativas, 
sino como un movimiento de trabajadores con pretensiones de incorporar otras experiencias organizativas de los denominados sectores populares. De esta forma se constituyó el Movimiento Nacional de Empresas Recuperadas (MNER) y, en una línea similar, el Movimiento Nacional de Fábricas Recuperadas por sus Trabajadores (MNFRT).

Por lo dicho anteriormente, entre los años de crisis (2001-2002) el centro del conflicto social parecía residir en los sectores informales en crecimiento, y no tanto en el sector formal de la clase obrera (Schuster y Nardacchione, 2005). Sin embargo, en plena crisis social, una fracción del sindicalismo hegemónico se movilizó contra la política económica de ajustes estructurales del gobierno de la Alianza, aunque en 2002 la protesta sindical fue protagonizada, casi exclusivamente, por la CTA. Las movilizaciones junto con la CCC mostraban a la CTA como el único sector sindical con capacidad y voluntad organizativa para realizar protestas callejeras (Godio, 2006). Sin embargo, la movilización obrera contestataria tenía un claro predominio de los sectores informales y/o precarizados.

\subsection{Escenario poscrisis}

A partir de 2003 se observa un resurgir del conflicto liderado por obreros formales y relativamente privilegiados en relación a la gran proporción de trabajadores informales. El gobierno de Kirchner (2003-2007) afrontó con éxito el desafío de detener la movilización y su poder destituyente, y sentar las bases de un nuevo modelo económico, esto es, rearticular una respuesta político-estatal frente a la movilización no institucionalizada (Biglieri y Perelló, 2007). Ello implicó la incorporación de un conjunto de demandas que animaban las movilizaciones sociales de la época, junto con un reconocimiento mayor de los nuevos actores sociales involucrados, lo que supuso el resurgir del movimiento obrero organizado. Con relación a los asalariados, se recompusieron los ingresos de activos y pasivos con el objetivo de aumentar la demanda y apuntalar el crecimiento de la economía que se registraba en el primer semestre de 2003. A la vez, se impulsaron los convenios colectivos entre sindicatos y empresarios, lo cual le dio un renovado protagonismo político al movimiento obrero (Godio, 2006). De esta manera, el conflicto laboral tuvo, a partir de 2003, las siguientes características: 1) estuvo centrado en trabajadores del sector privado, revirtiendo la tendencia anterior de predominio de protestas de trabajadores estatales organizados en torno a la CTA;2) mermaron las protestas en respuesta a decisiones de políticas públicas y aumentaron las disputas salariales y por condiciones de trabajo; 3) predominaron las huelgas de naturaleza económica más que huelgas políticas (Etchemendy y Collier, 2007). 
Las condiciones inmediatas del resurgir del movimiento obrero sindicalizado se hallan en el crecimiento del empleo y en el rol más activo de parte del Estado, liderado por un gobierno que buscó el apoyo de los sindicatos. Las condiciones de largo plazo de este resurgimiento se vinculan a la forma en que los sindicatos se adaptaron al neoliberalismo de la etapa previa. En primer lugar, los sectores que conforman en este período la vanguardia del sindicalismo argentino fueron los que más crecieron durante la etapa liberalizadora, a la vez que experimentaban altas tasas de sindicalización, prácticas de negociación colectiva y experiencia militante (sectores de alimentos, transporte, petróleo). Por tanto, pudieron activarse con la recuperación económica y política. En segundo lugar, durante el menemismo lograron acuerdos institucionales (un marco para las negociaciones salariales centralizadas, mantener el monopolio de la representación a nivel de planta, y la administración de las obras sociales para los trabajadores) que les permitieron conservar el poder asociativo de los sindicatos, y utilizarlo luego en un contexto más favorable.

Los efectos principales de la recuperación de la movilización sindical han sido los siguientes: 1 ) se ha reestablecido a los dirigentes sindicales como interlocutores válidos del gobierno y de las asociaciones empresariales en las negociaciones salariales a nivel de cúpula; 2) se ha incrementado la capacidad de movilización y las prerrogativas institucionales de los sindicatos; 3 ) se ha ayudado a porciones de los trabajadores formales a recomponer su escala salarial, y 4) como no existe el componente de política social, se ha fortalecido la brecha entre los trabajadores que pertenecen a estos sindicatos y quienes están en el sector informal del mercado.

En este marco, mientras el movimiento piquetero se va debilitando por el aumento del empleo, el movimiento de empresas recuperadas se consolida como experiencia colectiva, a la vez que se desarrollan algunas mutaciones en sus formas político-organizativas. El MNER era la organización mayoritaria hacia 20042005 (Ruggeri, 2005; Rebón, 2004). A partir de esta época padeció un proceso de descomposición política que concluyó con su virtual agotamiento desde los inicios de 2006. Unos años antes se había desarticulado el FEENCOTER, así como el espacio conducido por la izquierda a favor de la estatización con control obrero de la producción. De las primeras organizaciones del movimiento, por tanto, se mantiene hasta la actualidad el MNFRT. Los motivos de las crisis políticas y desmoronamientos organizativos del movimiento hacia mediados de la década de 2000 remiten a una incapacidad política general de conformar un espacio unificado, asumiendo y procesando internamente las diferencias y heterogeneidades de un movimiento complejo, pero con intereses objetivos comunes. 
Sin embargo, tras estos primeros fracasos político-organizativos se están erigiendo nuevas organizaciones con voluntad de conducir el movimiento. La novedad de las nuevas organizaciones que se conformaron en los últimos años es que prevalece el criterio, inicialmente pragmático, de asumir formatos provenientes del movimiento cooperativo. En esta línea se inscribe la Federación Argentina de Cooperativas de Trabajadores Autogestionados (FACTA). También se encuentra la Federación de Empresas Recuperadas y Cooperativas de Trabajo (FERyCOOTRA). Dicha federación se conformó bajo la impronta política de un sindicato metalúrgico, la Unión Obrera Metalúrgica de Quilmes, que conduce a un grupo importante de empresas recuperadas. Otro espacio que se ha conformado es la Federación de Cooperativas de Trabajo Red Gráfica Cooperativa Limitada, constituida por empresas recuperadas del sector gráfico, y políticamente integrada con la Federación de Cooperativas de Trabajo (FECOOTRA) y con el sindicato gráfico Federación Gráfica Bonaerense (FGB).

Sin embargo, otros espacios políticos no asumen la forma de federación de cooperativas, como la Asociación Nacional de Trabajadores Autogestionados (ANTA-CTA), que se conformó a fines de 2005 y está integrada por cerca de 80 organizaciones autogestionarias. Esta organización intenta constituirse en un sindicato de trabajadores autogestionados, promovido por la Central de Trabajadores Argentinos (CTA). La unidad entre estas organizaciones ha cristalizado débilmente en la Unión de Federaciones de Cooperativas de Trabajo, que agrupa a las federaciones mencionadas junto a otras tradicionales y aquellas cooperativas nacidas de los planes estatales de construcción de viviendas populares (Acosta y Raspall Galli, 2008). Así, se observa una evolución de un sector importante de empresas recuperadas desde posiciones que concebían al cooperativismo como una solución pragmática, adecuada al contexto de oportunidades presentado, hacia una concepción de naturaleza estratégica vinculada con las potencialidades de la economía social.

De la apretada síntesis descriptiva de la movilización social urbana en Argentina, observamos que el movimiento obrero sindicalizado ha retomado su centralidad, en un renovado contexto de negociaciones colectivas (Godio, 2008), a la vez que las protestas y movilizaciones contestatarias y destituyentes han perdido el lugar destacado que supieron ocupar con la implosión del neoliberalismo a comienzos de la década de 2000. Sin embargo, se mantienen novedosas estrategias de lucha obrera, como la recuperación de empresas, que adquieren un carácter institucionalizado. En este sentido, como balance global, la compleja manifestación de un sujeto popular se vio limitada y fragmentada por la implementación de políticas neoliberales pero, a su vez, la nueva estructura social argentina creó 
las condiciones para novedosas experiencias organizativas y lógicas de acción colectiva, que se canalizaron con los recursos, oportunidades y marcos de interpretación disponibles para las distintas clases sociales en el contexto analizado. La evolución registrada ha marcado un sendero iniciado en luchas defensivas, de resistencia al programa neoliberal, que se profundizaron al calor de la crisis orgánica del Estado nacional, adquiriendo niveles masivos y destituyentes de movilización, hasta la relativa «normalización» del conflicto en el contexto de una recomposición hegemónica del Estado.

\section{A modo de conclusión}

El neoliberalismo ha sido la doctrina político-económica que ha guiado la acción de los gobiernos de la práctica totalidad de los países del mundo, aunque con distinto grado de amplitud e intensidad y con concreciones prácticas con frecuencia contradictorias. Esta acción explica que «la globalización sigue siendo una opción, no un hecho. Es una opción tomada por gobiernos que deciden conscientemente reducir las barreras al comercio y a la inversión, adoptar nuevas políticas hacia las monedas y las finanzas internacionales y proyectar nuevas trayectorias económicas» (Frieden, 2007: 13). La globalización neoliberal es, tal y como se observa en el caso argentino, un programa político llevado adelante esencialmente por el Estado, y su objetivo ha sido «restablecer las condiciones para la acumulación de capital y restaurar el poder de las élites económicas» (Harvey, 2007: 32). Dicho programa, a su vez, permite captar las claves de la acción colectiva, especialmente en regiones donde el desarrollo capitalista ha sido incompleto; regiones en las que se da una distancia «entre los valores posmaterialistas y las necesidades básicas; entre las críticas al consumo y las críticas a la falta de consumo, entre el hiperdesarrollo y el subdesarrollo, entre la alienación y el hambre, entre la nueva clase media y las (poco esclarecedoras) clases populares, entre el Estado-providencia y el Estado-autoritario» (De Sousa Santos, 2001: 180). Por lo demás, el caso argentino, dada su condición de experiencia de laboratorio neoliberal, es clave para comprender los conflictos de clase actuales y al capitalismo en general; pero solamente si entendemos la clase como polo del antagonismo social, como lucha, y es que la existencia del capital es la lucha de clases (Holloway, 2004).

Por otra parte, los nuevos movimientos sociales que surgieron en América Latina desde mediados de la década de 1990 (zapatismo, piqueteros, empresas recuperadas, movilizaciones indígenas en los países andinos, etc.) abren un nuevo ciclo de movilizaciones y contestaciones al modelo neoliberal. Son movimientos (Wallerstein, 2002) que buscan transformaciones fundamentales en las relacio- 
nes sociales. Concretamente son movimientos que surgen de la crisis social, desposeídos o amenazados por la expropiación de sus tierras, de sus trabajos, de sus condiciones de vida, y por tanto son organizaciones que se constituyen a partir de la identificación política de su desposesión — como los movimientos de desocupados, los sin tierra, los sin techo-, o bien emergen tanto de las condiciones sobre las que se erige la opresión - el caso de los pueblos indígenas- como de la lógica comunitaria de vida amenazada: las asambleas ciudadanas, los movimientos de pobladores, etc. Por consiguiente, son movimientos con características distintivas que se diferencian de los del pasado, tanto en sus formas de lucha y organización como en sus reivindicaciones, etc. Sin embargo, mantienen la ligazón estructural con el capitalismo hegemónico y, por ello, constituye un desafío estudiar los vasos comunicantes entre las «nuevas» reivindicaciones y las «viejas» formas de lucha. Según Wallerstein (1999: 78), los «viejos» movimientos actúan según la «estrategia en dos pasos», como la orientada en primer lugar a «ganar al poder dentro de la estructura estatal; y segundo, y sólo después, transformar el mundo». En contra, los «nuevos» movimientos, que Wallerstein (1999: 82) reconoce como un producto paneuropeo - elemento central a la hora de aplicar esta categoría a América Latina-, se basan «en su vigoroso rechazo a la estrategia en dos pasos, propio de la vieja izquierda, lo mismo que a las jerarquías internas y a las prioridades de estas últimas - como la idea de que las necesidades de las mujeres, de las minorías y del medio ambiente eran secundarias y deberían ser consideradas sólo hasta 'después de la revolución'. Y en segundo lugar, estos nuevos movimientos sociales sospechaban profundamente del Estado así como de la acción orientada en referencia a ese mismo Estado».

Paradójicamente, una de las claves del nuevo escenario de gobiernos «nacional populares» y/o de «izquierda» en Latinoamérica a partir del siglo xxi fue el rol que desempeñaron los movimientos sociales, las organizaciones civiles, las redes de acción ciudadana y las protestas populares. Especialmente en el caso de Argentina, las movilizaciones novedosas y contestatarias (asambleas populares, piqueteros, ahorristas estafados, empresas recuperadas, trabajadores organizados) se desplegaron, configurando un campo especifico, en el contexto de una profunda crisis de las capacidades estatales y de autoridad política (Sidicaro, 2000). Sin embargo, desde el año 2003 el gobierno ha echado mano selectivamente a estrategias activas de reconocimiento y concesiones a los actores movilizados, en el marco de una estrategia de construcción de poder político al margen de las élites tradicionales (Gómez, 2006). De esta forma, existe un complejo proceso de paulatina reconstrucción estatal con un mayor margen relativo de maniobra frente a las clases dominantes. En este contexto, la recomposición de la autoridad política 
y de las capacidades de intervención estatales ha reducido el protagonismo de los movimientos sociales contestatarios al asumir parte de sus demandas.

Esta dialéctica entre movilizaciones y acción estatal se inscribe dentro de la perspectiva según la cual el conflicto social es un elemento constitutivo de la política. Ello no implica negar la necesidad de un conjunto de instituciones y procedimientos que le permiten a un Estado tomar decisiones vinculantes, ya que se trata de una concepción por la cual las formas de reglamentación posibilitan que la división social se exprese sin que el conflicto se convierta en violencia física. Pero, más alla de esta condición básica, el Estado se hace y rehace permantemente a través del conflicto. Esto es, la conflictividad y la movilización social contribuyen a la remodelación del Estado, de la misma forma que las políticas, estrategias y decisiones de éste constituyen oportunidades que incentivan la propia movilización (Tarrow, 1999). Por ello el conflicto social es una de las claves fundamentales del cambio social y político, mediante la dialéctica que vincula al Estado y la movilización (Offe, 1988). Es, en este sentido, que no se puede pensar la crisis del denominado «Consenso de Washington» en América Latina y el retorno de un Estado con mayores capacidades regulatorias sin considerar la decisiva influencia que han jugado las diferentes identidades sociales movilizadas, críticas y, en muchos casos, impugnadoras del anterior régimen social; un régimen que dio lugar a un intenso proceso de polarización socioeconómica tanto en el ámbito nacional como en el internacional, y ello mediante el proceso que Harvey (2004) denomina «acumulación por desposesión», esto es, mediante la transferencia de riqueza desde los trabajadores asalariados a los grandes capitalistas. De ahí que, como indica O'Connor (2001), lo importante sea interpretar la movilización social a la luz de las contradicciones del capitalismo, trazando un paralelismo entre el histórico movimiento sindical y los nuevos movimientos sociales. En su momento, el movimiento sindical empujó al capitalismo hacia formas más sociales de fuerzas y relaciones de producción (por ejemplo, con la negociación colectiva). Tal vez se plantea ahora pensar que los nuevos movimientos, así como las renovadas formas de expresión y organización de las clases populares y trabajadoras, sean quienes puedan empujar al capital y al Estado hacia formas más sociales de la reproducción de las condiciones de producción.

\section{Bibliografía}

Acosta, M. y Raspall Galli, T. (2008). La articulación de las cooperativas de vivienda con el Estado y otros actores sociales, en Documento de Trabajo 61, Centro de Estudios de Sociología del Trabajo. 
Acuña, C. (1995). La nueva matriz politica argentina. Buenos Aires: Nueva Visión.

Almeyra, G. (2005)+ «Los movimientos sociales en Argentina, 1990-2005», Argumentos, 48/49: 43-68.

Auyero, J. (2002). La protesta. Retratos de la beligerancia popular en la Argentina Democrática. Buenos Aires: Libros del Rojas-UBA.

Azpiazu, D.; Basualdo, E., y Schorr, M. (2000). La reestructuración y el redimensionamiento de la producción industrial argentina durante las últimas décadas. Buenos Aires: FETIA-CTA.

Balestrini, N. y Moroni, P. (2008). La horda de oro (1968-1977). Madrid: Traficantes de Sueños.

Basualdo, E* (2006). Estudios de Historia Económica Argentina (desde mediados del siglo XX hasta la actualidad). Buenos Aires: Siglo XXI.

Beccaria, L. (2001). Empleo e integración social. Buenos Aires: Fondo de Cultura Económica.

Biglieri, P. y Perelló, G. (2007). En el nombre del pueblo. La reemergencia del populismo kirchnerista. México: UNSAM.

BloJ, C. (2004)+ «Presunciones acerca de una ciudadanía indisciplinada; asambleas barriales en Argentina», en Mato, D. (coord.), Politicas de ciudadanía y sociedad civil en tiempos de globalización. Venezuela: FACES.

Bonanotte, C. (1996). «Plan de convertibilidad y conflictividad laboral. Un estudio estadístico de los conflictos laborales en tiempos de crisis». Buenos Aires: Mimeo.

Bourdieu, P. (1997). Razones prácticas. Sobre la teoría de la acción. Barcelona: Anagrama.

Bourdieu, P. (1999). La miseria del mundo. Madrid: Akal.

Bourdieu, P. (2000). La distinción: criterios y bases sociales del gusto. Madrid: Taurus.

Bourdieu, P. (2002). Pensamiento y acción. Caracas: Monte Ávila Editores.

Bourdieu, P. (2008). Cuestiones de sociología. Tres Cantos: Akal.

Brunet, I. y Schilman, F. (2005). Convivir con el capital financiero: corralito y movimiento de ahorristas. España: Editorial Fundamentos.

Brunet, I. y Pizza, A. (2011). Capitalismo y subjetividad obrera. El movimiento de empresas recuperadas en Argentina. Madrid: Biblioteca Nueva/Minerva.

Centro de Estudios Legales y Sociales (1999). Derechos bumanos en la Argentina. Informe Anual Enero-Diciembre 1998. Buenos Aires: EUDEBA.

CAstel, R. (1997). La metamorfosis de la cuestión social. Una crónica del salariado. Buenos Aires: Paidós. 
Cifarelli, V;; Martínez, Ó; Rodríguez, G., y Romero, M. (2006). La situación laboral en los call center y los desafíos para su organización. Buenos Aires: Ediciones TEL.

Cifarelli, V. y Martínez, Ó. (2009). «Clase obrera y movimiento obrero en Argentina, situaciones y desafíos», Revista THEOMAI, 19: 97-117.

Coates, D. (2000). Models of capitalism: Growth and stagnation in the Modern Era. Cambridge: Polity Press.

Corcuff, P* (2009). «Pierre Bourdieu (1930-2002) leído de otra manera. Crítica social post-marxista y el problema de la singularidad individual», Cultura $y$ Representaciones Sociales, 7: 27-53.

Corcuff, P. y Mathieu, L. (2011). «Partidos y movimientos sociales ilusiones de la 'actualidad' a una puesta en perspectiva sociologica», Cultura y Representaciones Sociales, 10:6-29.

Dalmaroni, M. y MerbilhaÁ, M. (1999). «Memoria social e impunidad: los límites de la democracia», Revista Punto de Vista, 63: 5-22.

Damill, M.; Frenkel, R., y Rapetti, M. (2007). «La deuda argentina, default y reestructuración», en Boyer, R. y Neffa, J. (coord.), Salida de crisis y estrategias alternativas de desarrollo. La experiencia argentina. Buenos Aires: Miño y Dávila/CEIL PIETTE.

De Sousa Santos, B. (2001). «Los nuevos movimientos sociales», Revista OSAL, 5.

Dussell, I.; Finocchio, S., y Gojman, S.(1997). Haciendo memoria en el país de Nunca Más. Buenos Aires: EUDEBA.

Etchemendy, S. y Collier, R. (2007). «Golpeados pero de pieः resurgimiento sindical y neocorporativismo segmentado en Argentina (2003-2007)», Politics and Society, septiembre: 145-192.

FAIr, H. (2008). «El plan de Convertibilidad y el sindicalismo durante la primera presidencia de Menem», Trabajo y Sociedad. Indagaciones sobre el trabajo, la cultura y las prácticas politicas en sociedades segmentadas, 10:71-97.

FAJN, G. (2003). Fábricas y empresas recuperadas. Protesta social, autogestión y rupturas en la subjetividad. Buenos Aires: Centro Cultural de la Cooperación.

Farinetti, M. (1999). «¿Qué queda del movimiento obrero? Las formas de reclamo laboral en la nueva democracia argentina», Revista Trabajo y sociedad, $n^{\circ}$ 1, Vol. 1, junio-septiembre, disponible en <http://www.fhuc.unl.edu.ar/ olimphistoria/paginas/manual_2009/docentes/modulo2/texto7.pdf>

Fernández, A. (2006). Politica y subjetividad. Asambleas barriales y fábricas recuperadas. Buenos Aires: Tinta Limón. 
Fernández Steinko, A. (2002). Experiencias participativas en economía y empresa. Madrid: Siglo XXI.

Frieden, J. (2007). Capitalismo global. El trasfondo económico de la historia del siglo XX. Barcelona: Crítica.

Galcerán, M.(2009). Deseo (y) libertad. Una investigación sobre los presupuestos de la acción colectiva. Madrid: Traficantes de Sueños.

Godio, J. (2008). El tiempo de CFK. Entre la movilización y la institucionalidad, Buenos Aires: Corregidor.

Godio, J. (2006). El tiempo de Kirchner. Buenos Aires: Letra Grifa Ediciones.

Godio, J. (2000). Historia del movimiento obrero argentino (1870-2000). Buenos Aires: El Corregidor.

Gómez, M. (2006). «Crisis y recomposición de la respuesta estatal a la acción colectiva desafiante en la Argentina, 1989-2004», Revista Argentina de Sociología, 6: 88-128.

Hardt, M. y Negri, A. (2002). Imperio. Barcelona: Paidós.

Harvey, D. (2004). El nuevo imperialismo. Madrid: Akal.

Harvey, D. (2007). Breve historia del neoliberalismo. Madrid: Akal.

Holloway, J. (2004). Clase E Lucha. Antagonismo social y marxismo crítico. Buenos Aires: Ediciones Herramienta y Universidad Autónoma de Puebla.

Carreras, I; Nicolás y Cotarelo, M. (2003). «La insurgencia espontánea. Argentina, diciembre 2001. Descripción, periodización, conceptualización», PIMSA, DT 43.

Jelin, E. (1989). Los nuevos movimientos sociales. Mujeres. Rock Nacional. Derechos Humanos. Obreros. Barrios. Buenos Aires: Centro Editor de América Latina.

Keane, J. (2008). La sociedad civil global y el gobierno del mundo. Barcelona: Hacer.

KLachко, P. (2007) + «Las formas de organización emergentes del ciclo de rebelión popular de diciembre de 1993 a junio de 2002 en la Argentina», PIMSA, DT 66: 80-101.

Lobato, M. y Suriano, J. (2003). La protesta social en Argentina. Buenos Aires: FCE.

Luttwatt, E. (2003). Turbocapitalismo. Barcelona, Crítica.

Maceira, V. y Spaltenberg, R. (2001). «Una aproximación al movimiento de desocupados en el marco de las transformaciones de la clase obrera argentina», OSAL, septiembre: 24-29.

Mathieu, L. (2007). iLíespace des mouvements sociauxî, Politix, 77: 43-68. 
Mazzeo, M. (2004). Piqueteros, notas para una tipología. Buenos Aires: FISyP/ Manuel Suárez.

Melucci, A. (1994). «Asumir un compromiso: identidad y movilización en los movimientos sociales», Zona Abierta, 69: 153-180.

Michels, R. (1971). Les partis politiques, Paris, Flammarion.

Munck, R. (2002). Globalización y trabajo. La nueva «Gran Transformación». Barcelona: El Viejo Topo.

Muñoz, M.(2010). Sísifo en Argentina. Orden, conflicto y sujetos políticos. México: Plaza y Valdez.

Muñoz, M. (2009). «Crisis política y conflicto social en Argentinaः alcances y límites de un tipo de participación política no convencional», European Review of Latin American and Caribbean Studies, 87:63-92.

Murillo, M. (1997). «La adaptación del sindicalismo argentino a las reformas de mercado en la primera presidencia de Menem», Desarrollo Económico, 37(147): 419-446.

O'Connor, J. (2001). Causas naturales. Ensayos de marxismo ecológico. México, Siglo XXI.

Offe, C. (1988). Partidos políticos y nuevos movimientos sociales. Madrid: Sistema. Palermo, V. y Novaro, M. (1996). Politica y poder en el gobierno de Menem, Norma: Buenos Aires.

Piva, A. (2001). «La década 'perdida'. Tendencias de la conflictividad obrera frente a la ofensiva del capital (1989/2001)», Cuadernos del Sur, no 17, noviembre.

Quirós, J. (2008). «Piqueteros y peronistas en la lucha del Gran Buenos Aires: por una visión no instrumental de la política popular», Cuadernos de Antropología Social, 27: 113-131.

Rancière, J. (2005). La haine de la démocratie. Paris: La Fabrique.

RANDle, M. (1998). Resistencia civil. La ciudadanía frente a las arbitrariedades de los gobiernos. Buenos Aires: Paidós.

Rapoport, M. (2005). Historia económica, política y social de la Argentina (18802003). Buenos Aires: Editorial Emecé.

Rebón, J. (2004). Desobedeciendo al desempleo. La experiencia de las empresas recuperadas. Buenos Aires: Ediciones Picaso/La Rosa Blindada.

Rosanvallón, P. (1995). La nueva cuestión social: repensar el Estado Providencia. Madrid: Civitas.

Ruggeri, A. (2010). Las empresas recuperadas en Argentina 2010. Informe del tercer relevamiento de empresas recuperadas por sus trabajadores. Buenos Aires: Programa Facultad Abierta, UBA.

Schorr, M. (2004). Industria y Nación. Buenos Aires: Editorial Edhasa. 
Schuster, F. y Nardacchione, G. (2005). Tomar la palabra. Estudios sobre protesta social y acción colectiva en la Argentina contemporánea. Buenos Aires: Prometeo.

Senén Gonzáles, S. y Bosoer, F+ (1999). El sindicalismo en tiempos de Menem. Buenos Aires: El Corregidor.

Sidicaro, R. (2002). La crisis del Estado y los actores politicos y socioeconómicos en la Argentina (1989-2001). Buenos Aires: Eudeba.

Svampa, M. y Pereyra, S. (2003). Entre la ruta y el barrio. Las experiencias de las organizaciones piqueteras. Buenos Aires: Biblos.

TArrow, S. (1997). El poder en movimiento. Los movimientos sociales, la acción colectiva y la politica. Madrid: Alianza Universidad.

Touraine, A. (1985). «An Introduction to the Study of Social Movements», Social Research, 52 (4): 778-784.

Touraine, A. (1991). Los Movimientos Sociales. México: Ed. Almagesto.

Villarreal, J. (1985). «Los hilos sociales del poder», en Jozami, E.; Paz, P., y Villarreal, J. (coord.), Crisis de la dictadura argentina. Buenos Aires: Siglo XXI.

Wallerstein, I. (1999). «Los dilemas de los movimientos antisistémicos», en Arrighi, G.; Hopkins, T. K., y Wallerstein, I. (coord.), Movimientos antisistémicos, Madrid: Akal. 